\title{
The metabolic consequences of obstructive sleep apnoea in children
}

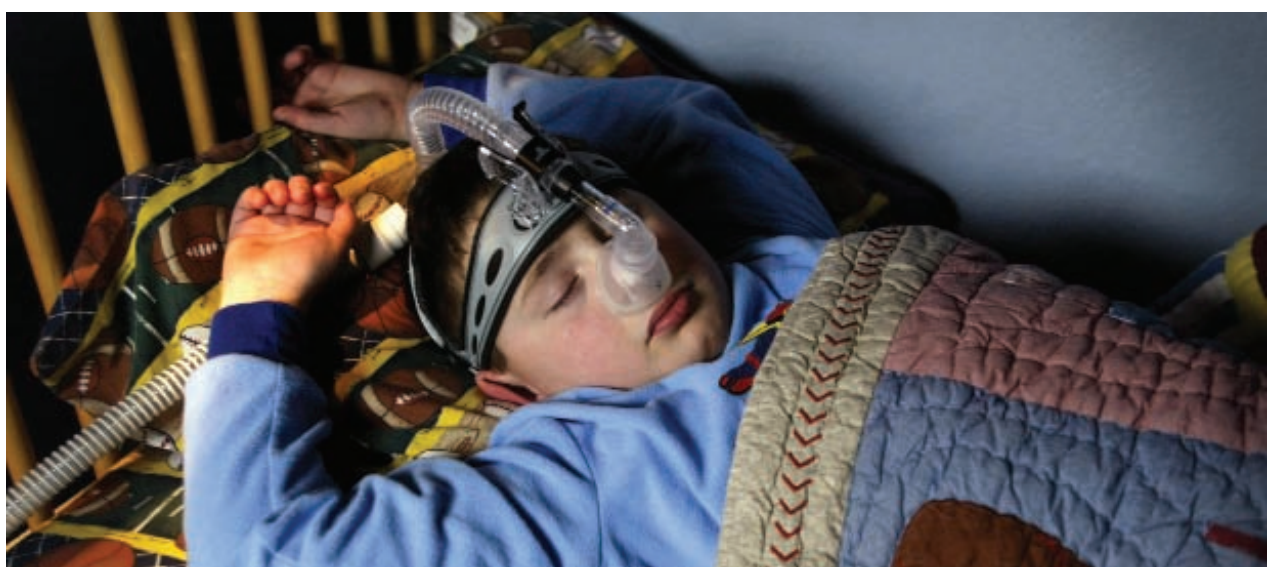

\section{S. Verhulst}

\section{Dept of Pediatrics}

University of Antwerp

Campus Drie Eiken - office T4.27

Universiteitsplein 1

Wilrijk

2610

Belgium

stijn.verhulst@ua.ac.be

\section{Educational aims}

1 To define the metabolic syndrome in the paediatric population.

1 To describe the long-term morbidity of paediatric metabolic syndrome in early adulthood.

1 To investigate the relationship between OSA and metabolic syndrome during childhood, across age ranges and across different degrees of obesity.

1 To identify future areas of research.

\section{Summary}

The metabolic syndrome is defined as the clustering of hyperinsulinaemia, obesity, hypertension and hyperlipidaemia. Its prevalence in the paediatric population in the US is estimated at $\sim 4 \%$, but this can rise to $20-50 \%$ in obese children. The presence of aspects of the metabolic syndrome in childhood is closely linked to factors such as obesity, insulin resistance and early signs of cardiovascular disease in young adulthood.

While in adults there is a strong relationship between sleep-disordered breathing and obesity, and hence with other factors associated with the metabolic syndrome, the evidence in children has not been as clear-cut, although factors such as arterial oxygen saturation $\left(\mathrm{S}_{1} \mathrm{O}_{2}\right)$ and apnoea-hypopnoea index $(\mathrm{AHI})$ have been shown to correlate with aspects of the metabolic syndrome.

Intervention studies in sleep-disordered breathing with metabolic syndrome, using adenotonsillectomy, continuous positive airway pressure (CPAP) and weight loss, have produced mixed results, and the optimum treatment remains unclear. Randomised controlled trials of these treatments, along with larger-scale and longitudinal studies to tease out the associations between sleep-disordered breathing, obesity and the metabolic syndrome in a paediatric context, are needed. 


\section{The metabolic syndrome}

The metabolic syndrome is defined as the clustering of hyperinsulinaemia, obesity, hypertension and hyperlipidaemia, all cardiovascular risk factors. Adults with the metabolic syndrome are at greater risk of cardiovascular morbidity and mortality, and have a five-fold increased risk of developing type 2 diabetes.

There are currently three main definitions of the metabolic syndrome [1-3], based on criteria such as abdominal obesity, triglyceride and highdensity lipoporotein cholesterol, blood pressure and fasting glucose. In children, these are modified according to age, sex, ethnicity or even centre-specific criteria.

In addition to the definitive criteria, a number of conditions co-occur frequently with the metabolic syndrome. These include: microalbuminuria, kidney dysfunction; nonalcoholic fatty liver disease, which is considered to be the hepatic manifestation of the metabolic syndrome; oxidative stress and inflammation; and hypercoagulability.

The triggers for the metabolic syndrome are similar to those for obesity. There is a very strong genetic predisposition, together with classic environmental factors such as excess calorie intake and reduced physical activity, leading to central obesity and insulin resistance.

\section{Paediatric context}

\section{Figure 1}

The effect of multiple riskfactors on the extent of atherosclerosis in the aorta and coronary arteries in children and young adults. Reproduced from [7], with permission from the publisher. Number of risk factors: $\square=0 ; \square=1 ; \square=2 ; \square=3$ or 4 . $* *: p<0.01 ; *: p<0.03$.
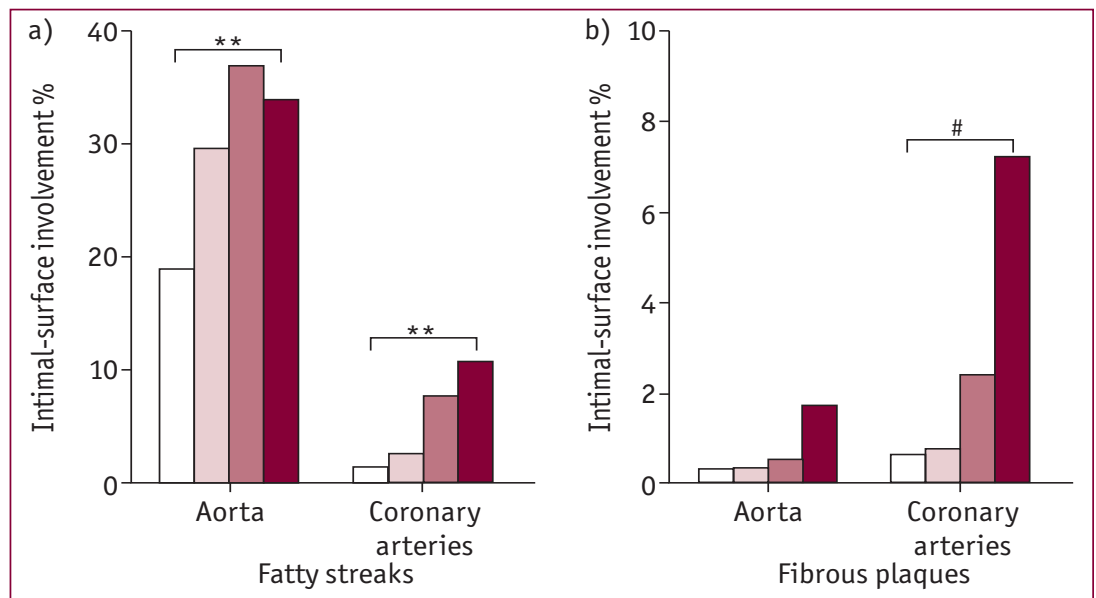

traumatic causes. The authors examined preatherosclerotic lesions - fatty streaks and fibrous plaques - in the aorta and coronary arteries of their subjects. They then correlated the extent of these lesions with a panel of ante mortem cardiovascular risk factor variables, such as body mass index (BMI), blood pressure and smoking, gathered from childhood medical notes. There was a close relationship between the number of risk factors present during childhood and the extent of the pre-atherosclerotic lesions (figure 1).

The other study [8] measured the blood pressure, weight and height of children at 13 yrs of age, then re-examined them, with additional measurements of lipid levels and insulin resistance. The study found that BMI at age 13 correlated well with that at age 22 , and also with insulin resistance.

These studies present two key messages. First, obese children tend to become obese adults. Secondly, and most importantly, the development of cardiovascular and metabolic disease begins in childhood and early adolescence.

\section{Sleep-disordered breathing Metabolic syndrome}

To date, two studies have investigated whether sleep-disordered breathing in children is an independent risk factor for the development of metabolic syndrome. The first of these [9], carried out by the present author's team, looked at $>100$ overweight or obese children at a paediatric obesity clinic. It transpired that the severity of sleepdisordered breathing was indeed a risk factor for the metabolic syndrome. Two parameters - mean $\mathrm{Sa}_{1} \mathrm{O}_{2}$ and nadir $\mathrm{Sa}_{1} \mathrm{O}_{2}$ during sleep - were independint predictors for the presence of the metabolic syndrome. In other words, the more 'normal' the $\mathrm{Sa}_{1} \mathrm{O}_{2}$ during sleep, the lower the risk of presenting with the metabolic syndrome.

These findings were replicated by a larger study performed in the USA [10]. Figure 2 shows the proportion of subjects with metabolic syndrome at different AHI levels. The two studies show that, in children as well as in adults, the severity of sleep-disordered breathing is associated with the metabolic syndrome.

\section{Insulin resistance}

Several studies have also addressed the relationship between the severity of sleep apnoea and insulin resistance, the core factor of the metabolic syndrome (for a review, see [11]). Here, the results 
are conflicting. Some studies found a relationship, others did not. Even when a relationship was present, it was usually small.

The effects of age and degree of obesity add another layer of difficulty. Studies of normalweight and morbidly obese children have failed to find an association between sleep apnoea and insulin resistance. However, the relationship does exist in moderately obese children. Meanwhile, in young children no relationship between sleepdisordered breathing and insulin resistance was found - it appears only in older children, suggesting that the duration of exposure to obesity and sleep-disordered breathing, or perhaps the hormonal changes of puberty, could have a role.

Intervention studies looking at sleep apnoea and insulin resistance have also produced conflicting results. In the largest before- and-after study on adenotonsillectomy in obese and nonobese children [12], a link was seen: in obese subjects whose obstructive sleep apnoea resolved completely, there was a significant improvement in many metabolic variables, such as insulin resistance, dyslipidaemia and inflammation. This was significantly better than the improvement seen in patients with residual sleep apnoea. However, two other studies $[13,14]$ found opposing or nonsignificant results.

\section{Treatment}

Discussion of intervention studies leads naturally to the topic of the best treatment. For an obese child with obstructive sleep apnoea and metabolic abnormalities, the ideal treatment should target both conditions.

\section{Adenotonsillectomy}

A recent meta-analysis [15] showed that adenotonsillectomy resolves obstructive sleep apnoea in less than $50 \%$ of obese children. Furthermore, there is often a significant postoperative increase in BMI, which may worsen metabolic problems.

\section{CPAP}

The data on CPAP are very scarce, and there are persistent questions over long-term compliance in children. The study by NAKRA et al. [16] suffered from poor compliance, although the report did produce some interesting findings. No improvement in insulin resistance was seen, but leptin levels fell significantly, therefore the treatment did have some effect in children with sleep-disordered breathing.

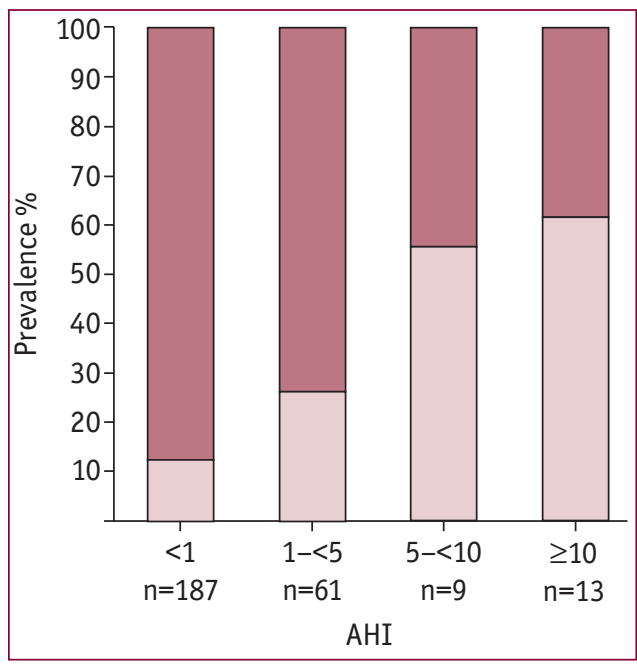

\section{Weight loss}

Although the effect of weight loss does seem to be very promising in children the only studies to examine this have looked either at bariatric surgery or at children undergoing inpatient treatment. There is no data about the effect of weight loss on sleep apnoea in children aged $<10$ yrs. There is no data about modest weight loss and again, as always with weight loss, there is a question about long-term compliance.

To give an example, the present author's group studied the effect of weight loss therapy in resolving sleep apnoea in obese teenagers [17]. The success rate ranged from $62-91 \%$, depending on the definition of success. Whichever measure is taken, this is a better rate than that of adenotonsillectomy.

\section{Conclusions and next steps}

In conclusion, sleep-disordered breathing is indeed associated with metabolic dysregulation in children, but this is dependent on the degree of obesity and the age of the subject. More largescale studies are needed to tease out the effect of these variables. Furthermore, the correlations in general between sleep-disordered breathing and metabolic dysregulation in children are relatively small, so the long-term health consequences of sleep-disordered breathing in children remain unknown. For this, logitudinal studies are needed.

Is there a need for a specific treatment? Well, weight loss is certainly important, but that does not mean adenotonsillectomy should be wholly abandoned. Perhaps a combination of the two might prove effective. Randomised controlled trials are needed.
Figure 2

Prevalence of the metabolic syndrome in increasingly severe categories of sleep-disordered breathing, as defined by increasing levels of the AHI. A linear association $(p<0.001)$ was demonstrated between the metabolic syndrome and AHI category. $\square$ : non-metabolic syndrome; $\square$ : metabolic syndrome. Reproduced from [10], with permission from the publisher. 
It is also known that sleep-disordered breathing interacts with oxidative stress and inflammation, and with leptin, and studies are ongoing regarding the mechanisms. In addition, the role of the adipose tissue, which secretes a number of adipocytokines that have a huge effect on a range of end-organs, remains to be fully elucidated. The effect of intermittent hypoxia on the fatty tissue is a very interesting question for the next few years.

\section{References}

1. Expert Panel on Detection, Evaluation, and Treatment of High Blood Cholesterol in Adults. Executive Summary of the Third Report of the National Cholesterol Education Program (NCEP) Expert Panel on Detection, Evaluation, and Treatment of High Blood Cholesterol in Adults (Adult Treatment Panel III). JAMA 2001; 285: 2486-2497.

2. World Health Organization. Definition, diagnosis and classification of diabetes mellitus and its complications. Report of a WHO consultation, Part 1: Diagnosis and classification of diabetes mellitus. Geneva, World Health Organization, 1999. http://whqlibdoc.who.int/hq/1999/WHO_NCD_NCS_99.2.pdf

3. International Diabetes Federation. The IDF consensus worldwide definition of the metabolic syndrome. Brussels, International Diabetes Federation, 2006. www.idf.org/webdata/docs/MetS_def_update2006.pdf

4. Cook S, Weitzman M, Auinger P, Nguyen M, Dietz WH. Prevalence of a metabolic syndrome phenotype in adolescents: findings from the third National Health and Nutrition Examination Survey, 1988-1994. Arch Pediatr Adolesc Med 2003; 157: 821-827.

5. Weiss R, Dziura J, Burgert TS, et al. Obesity and the metabolic syndrome in children and adolescents. $N$ Engl $\mathrm{J}$ Med 2004; 350: 2362-2374.

6. Invitti C, Maffeis C, Gilardini L, et al. Metabolic syndrome in obese Caucasian children: prevalence using WHOderived criteria and association with nontraditional cardiovascular risk factors. Int J Obes 2006; 30: 627-633.

7. Berenson GS, Srinivasan SR, Bao W, Newman WP 3rd, Tracy RE, Wattigney WA. Association between multiple cardiovascular risk factors and atherosclerosis in children and young adults. The Bogalusa Heart Study. N Engl J Med 1998; 338: 1650-1656.

8. Steinberger J, Moran A, Hong CP, Jacobs DR Jr, Sinaiko AR. Adiposity in childhood predicts obesity an insulin resistance in young adulthood. J Pediatr 2001; 138: 469-473.

9. Verhulst S, Schrauwen N, Haentjens D, et al. Sleep-disordered breathing and the metabolic syndrome in overweight and obese children and adolescents. J Pediatr 2007; 150: 608-612.

10. Redline S, Storfer-Isser A, Rosen CL, et al. Association between metabolic syndrome and sleep-disordered breathing in adolescents. Am J Respir Crit Care Med 2007; 176: 401-408.

11. Verhulst S, Rooman R, Van Gaal L, De Backer W, Desager K. Is sleep-disordered breathing an additional risk factor for the metabolic syndrome in obese children and adolescents? Int J Obes (Lond) 2009; 33: 8-13.

12. Gozal D, Capdevila OS, Kheirandish-Gozal L. Metabolic alterations and systemic inflammation in obstructive sleep apnea among nonobese and obese prepubertal children. Am J Respir Crit Care Med 2008; 177: 1142-1149.

13. Kaditis AG, Alexopoulos EI, Damani E, et al. Obstructive sleep-disordered breathing and fasting insulin levels in nonobese children. Pediatr Pulmol 2005; 40: 515-523.

14. Waters KA, Sitha S, O'Brien LM, et al. Follow-up on metabolic markers in children treated for obstructive sleep apnea. Am J Respir Crit Care Med 2006; 174: 455-460.

15. Costa DJ, Mitchell R. Adenotonsillectomy for obstructive sleep apnea in obese children: a meta-analysis. Otolaryngol Head Neck Surg 2009; 140: 455-460.

16. Nakra N, Bhargava S, Dzuira J, Caprio S, Bazzy-Asaad A. Sleep-disordered breathing in children with metabolic syndrome: the role of leptin and sympathetic nervous system activity and the effect of continuous positive airway pressure. Pediatrics 2008; 122: e634-e642.

17. Verhulst S, Franckx H, Van Gaal L, De Backer W, Desager K. The effect of weight loss on sleep-disordered breathing in obese teenagers. Obesity (Silver Spring) 2009; 17: 1178-1183. 